\title{
The Research on the Effect of Water Content on Soil Shrinkage Rui Ma ${ }^{1,2, \text { a }}$, Huanzhuang Tao ${ }^{1,2, ~ b, ~}{ }^{*}$, Jingju Zhang ${ }^{1,2}$, Dan Huang ${ }^{1,2}$, Fangli Cheng $^{3}$ \\ ${ }^{1}$ Guangxi Scientific Experiment Center of Mining, Metallurgy and Environment, Guilin University of Technology, Guilin 541004, China \\ ${ }^{2}$ Guangxi Key Laboratory of Environmental Pollution Control Theory and Technology, Guilin University of Technology, Guilin 541004, China \\ ${ }^{3}$ Guilin Institute of Agricultural Sciences, Guilin 541004, China \\ a632444931@qq.com, b799634972@qq.com \\ "Corresponding author
}

Keywords: Soil Shrinkage Curve, Moisture Content

\begin{abstract}
This paper taking sugar cane, pear tree and soybean plots as an example, using software SSS to fit soil shrinkage curve, studies the effect of moisture content in the field on soil shrinkage. The results show that the model parameters of SSS software could fit the measured data well( $r>0.95)$ with relatively small error; the differences of soil shrinkage between three upland crops successfully verify that the capacity of soil shrinkage directly proportional to moisture content, particularly to initial moisture content.
\end{abstract}

\section{Introduction}

With the condition of rainfall, evaporation and manual irrigation, Soil is usually in the state of wet-dry cycling, which could be accompanied with expansion and contraction [1]. In particular, the dehydration process from saturation to desiccation could contribute to cracking and surface subsidence of soil, increasing soil surface area, the rate of evaporation and drying of soil; which also leads to the infiltration of water and nutrients, the reduction in utilization of water and fertilizer, and increases a pollution risk of groundwater [2].

Soil shrinkage process commonly used the value of volume change and soil water content or void ratio and moisture ratio as the dependent and independent variables for describing. Peng and Horn [3] on the basis of Van Genuchten equation modified and got a Logistic model, which could integrally describe shrinkage curve, and make a quantitative distinction by operation of each shrinkage phase.

Surface soil plays a significant role in the exchange of energy and material between land surface and atmosphere, which not only could recharge its nutrients and moisture to subsoil, but also offer to the growth of crops, with a certain research value. This article taking three plots as an example, analyses the process of soil shrinkage from saturation to air dry and the influential factor causing the shrinkage differences, in order to provide theoretical basis for soil physical properties.

\section{Materials and experimental}

\subsection{The overview of Experiment Area and The determination of Soil in 3 Crops}

The academy of agricultural sciences $\left(25^{\circ} 4^{\prime} \mathrm{N} ; 109^{\circ} 44^{\prime} \mathrm{E}\right)$ of Guilin is used as an experimental area in this paper, which is in subtropical monsoon climate, its mean annual temperature 18 degrees Celsius, its mean annual rainfall $1949 \mathrm{~mm}$, its mean evaporation ranging from 1490 to $1905 \mathrm{~mm}$.

The sample plots were selected in the same region, planting sugarcane, pear tree and soybean, respectively. Sugarcane is an annual or pernnial and tropical or subtropical root herb; soybean is an annual herbaceous plant; pear tree is pernnial deciduous fruit crop. The water content of topsoil $(0 \sim 6 \mathrm{~cm})$ in the field was measured by using handhekd soil moisture content analyser. The 
undisturbed topsoil samples were conducted for determining soil shrinkage, meanwhile, soil basic data such as soil texture, bulk density, total porosity and soil organic matter were estimated in the laboratory.

\subsection{The fitting curve of soil shrinkage}

The equation of soil shrinkage curve had been modified by Peng and Horn [3], which was first forwarded by van Genuchten as follows:

$$
e(\vartheta)=e_{r}+\frac{e_{s}-e_{r}}{\left[1+(\chi \vartheta)^{-p}\right]^{p}} \quad 0 \leq \vartheta \leq \vartheta_{s}
$$

Where $\vartheta_{s}, e_{s}$ and $e_{r}$ are the saturated moisture ratio, the saturated and residual void ratio, respectively. Where $\chi, p, q$ are dimensionless fitting parameters. These zones of the shrinkage curve can be defined as: structural, proportional, residual, as well as zero shrinkage, respectively.

\section{Results}

\subsection{The Soil Basic Properties}

Table1 The soil texture, bulk density (BD), soil organic matter (SOM) and total porosity in three plots

\begin{tabular}{ccccccc}
\hline Plots & Sand $/ \%$ & $\begin{array}{c}\text { Texture } \\
\text { Silt } / \%\end{array}$ & Clay $/ \%$ & $\begin{array}{c}\text { BD/ } \\
\left(\mathrm{g} \cdot \mathrm{cm}^{-3}\right)\end{array}$ & $\begin{array}{c}\text { SOM/ } \\
\left(\mathrm{g} \cdot \mathrm{kg}^{-1}\right)\end{array}$ & $\begin{array}{c}\text { Total Porosity/ } \\
\%\end{array}$ \\
\hline Sugarcane & $35.67 \pm 2.72 a$ & $26.28 \pm 1.72 a$ & $38.05 \pm 2.10 a$ & $1.43 \pm 0.019 a$ & $13.35 \pm 0.72 a$ & $43.78 \pm 0.73 b$ \\
Pear tree & $37.32 \pm 0.11 a$ & $26.19 \pm 3.43 a$ & $36.49 \pm 3.54 a$ & $1.30 \pm 0.018 b$ & $15.29 \pm 0.34 a b$ & $48.41 \pm 0.53 a$ \\
Soybean & $35.32 \pm 0.61 a$ & $27.59 \pm 1.87 a$ & $37.09 \pm 1.25 a$ & $1.44 \pm 0.010 a$ & $11.42 \pm 0.77 b$ & $42.48 \pm 0.63 b$ \\
\hline
\end{tabular}

Note: Different lowcase letters indicate the significant difference $(P<0.05), n=4$.

The table 1 shows us that the composition of soil particles of three plots was similar, and the soil texture had little difference, illustrating a situation that the differences of other soil properties were caused by planting different crop varieties. The significant analysis of bulk density indicated that the values of sugarcane plot and soybean plot were larger, and the value of pear tree plot was the smallest. From the significant analysis of total soil porosity, the value of pear tree plot was the biggest, and the differences between sugarcane plot and soybean plot were not obvious. In terms of soil texture, it was the lowest in soybean plot, and the largest in pear tree plot, which was related to litterfall at the surface and weeds.

\subsection{The Soil Water Content in the Field}

As we can see in Figure 1,there are obvious abrupt changes among three curves. From September 10 to October 31 and November 13 to December26, as well as January 4, the trend of soil water content totally was on a decling curve, rapidly in the plots of sugarcane and soybean, comparatively slow in pear plot. From November 3 to 13 and December 29, these curves became obvious steeper, and the increased rate became greatly. The curves of sugarcane and soybean plots increased rapidly than pear tree plot's owing to less surface mulch. 


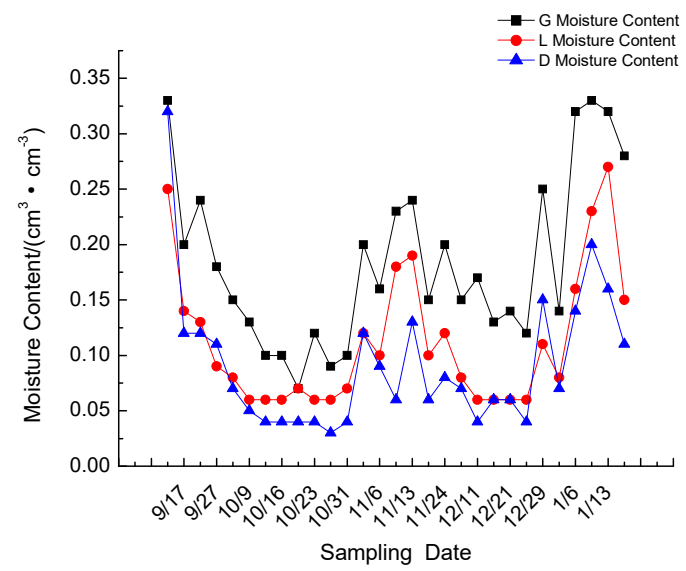

Fig.1 The variation of soil moisture with time under three plots

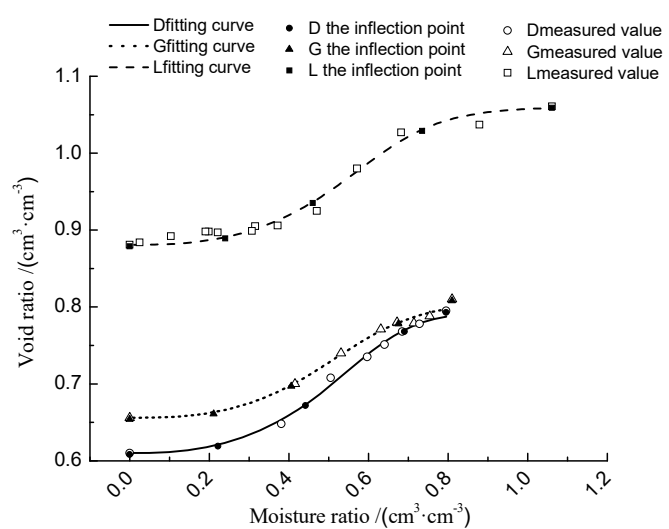

Fig. 2 The shrinkage curve under the condition of natural air drying in three fields(G, L and D represent sugarcane, pear tree and soybean plots, respectively.)

As shown in Figure 1, in the overwhelming majority of cases, the curve was at the top in pear tree plot, at the bottom in soybean plot, which illustrated that soil water content of three plots from high to low were pear tree plot's, sugarcane plot's, soybean plot's.

Table 2 The soil moisture content under three kinds of soil water condition in 3 plots

\begin{tabular}{ccccc}
\hline Water Conditions & Plots & $\begin{array}{c}\text { Minimum/ } \\
\left(\mathrm{cm}^{3} \cdot \mathrm{cm}^{-3}\right)\end{array}$ & $\begin{array}{c}\text { Maximum/ } \\
\left(\mathrm{cm}^{3} \cdot \mathrm{cm}^{-3}\right)\end{array}$ & $\begin{array}{c}\text { Mean/ } \\
\left(\mathrm{cm}^{3} \cdot \mathrm{cm}^{-3}\right)\end{array}$ \\
\hline \multirow{3}{*}{ Drought Condition } & Soybean & 0.01 & 0.10 & $0.04 \pm 0.02 c$ \\
& Pear tree & 0.05 & 0.22 & $0.10 \pm 0.04 a$ \\
& Sugarcane & 0.01 & 0.12 & $0.06 \pm 0.002 b$ \\
& Soybean & 0.02 & 0.21 & $0.12 \pm 0.005 b$ \\
Medium Condition & Pear tree & 0.12 & 0.29 & $0.20 \pm 0.004 a$ \\
& Sugarcane & 0.01 & 0.29 & $0.12 \pm 0.006 b$ \\
& Soybean & 0.15 & 0.36 & $0.20 \pm 0.004 c$ \\
Humid Condition & Pear tree & 0.18 & 0.46 & $0.33 \pm 0.007 a$ \\
& Sugarcane & 0.12 & 0.35 & $0.23 \pm 0.006 b$ \\
\hline
\end{tabular}

Note: Different lowcase letters indicate the significant difference $(\mathrm{P}<0.05), \mathrm{n}=80$

The table 2 shows us that there was some difference of field soil moisture in three types of grown crops, and the variations in means under different soil moisture conditions from high to low were pear tree plot's, sugarcane plot's, soybean plot's.

\subsection{The soil shrinkage curve}

Soil shrinkage curves in the condition of natural air drying in three plots are shown in Figure 2. As we can see in Figure 2, soil shrinkage kept closer between sugarcane field and soybean field, but 
significantly higher in pear plot than two other plots's. The fitting coefficients (r) were all greater than 0.95, which illustrates the equation fitted well. The $e_{s}$ and $e_{r}$ were the largest in soil shrinkage curve of pear tree plot, and more close between sugarcane plot and soybean plot.

According to calculating data, in structural shrinkage state, the volume changes corresponding to the water loss in sugarcane plot and soybean plot were close, and larger than pear tree plot's; in proportional shrinkage state, the value was the biggest in pear plot, and not appeared to be much different between two other plots; in residual shrinkage state, the same trend was obtained as proportional shrinkage state; in zero shrinkage, the value had remained the largest in pear plot.

Proportional shrinkage state was the main parts $(51 \% \sim 53 \%)$ of shrinkage curve, followed by residual shrinkage $(22 \% \sim 29 \%)$, structural shrinkage $(12 \% \sim 20 \%)$, and lastly zero shrinkage $(4 \% \sim 6 \%)$. Therefore, the proportion of proportional shrinkage and residual shrinkage were the highest, which could use as an important index to assess soil shrinkage degree of three plots .From the above, soil shrinkage in pear tree plot was basically larger than two other parties.

\section{Conclusion}

Physiological characteristics of pear tree protect its soil surface from sunlight exposure, and decrease its evaporation, comparing with two other crops, its soil water content was the highest one. Meanwhile, ground surface mulchs also have the effect in water conservation, which contributes to storaging soil water content of pear tree field. Therefore, high water content made soil shrinkage of pear tree plot to be the most obvious one. There was little difference of moisture content between sugar cane and soybean plots, which is consistent with the result that the changes of shrinkage curve were similar and less than pear tree plot's. Therefore, the results successfully verify that the capacity of soil shrinkage is proportional to moisture content, particularly to initial moisture content.

\section{Acknowledgements}

The author thank the support of the project of high level innovation team and outstanding scholar in Guangxi colleges and universities, and Natural Science Foundation of Guangxi (No. 2014GXNSFBA118098).

\section{References}

[1]. S E YANG, Y F HUANG, Discussion on Soil Shrinkage Characteristic Curves, Chinese Journal of Soil Science. 38 (2007) 749-752.

[2]. Z B ZHANG, X PENG, L L WANG, et al, Temporal changes in shrinkage behavior of two paddy soils under alternative flooding and drying cycles and its consequence on percolation, Geoderma. 192 (2013) 12-20.

[3]. X PENG, R HORN, Modeling soil shrinkage curve across a wide range of soil types, Soil Science Society of America Journal. 69 (2005) 584-592. 